\title{
INEQUALITIES INVOLVING MULTIVARIATE CONVEX FUNCTIONS IV
}

\section{EDWARD NEUMAN}

Abstract. This paper deals with the inequalities involving logarithmically convex functions of several variables. The results here provide generalizations of inequalities for univariate functions obtained by Dragomir and Dragomir and Mond.

Mathematics subject classification (2010): 26D15, $26 \mathrm{~B} 25$.

Keywords and phrases: Convex and logarithmically convex functions, Hermite-Hadamard inequality, generalized simplex splines, weighted logarithmic mean, inequalities.

\section{REFERENCES}

[1] B. C. Carlson, Special Functions of Applied Mathematics, Academic Press, New York, 1977.

[2] W. Dahmen and C. A. Micchelli, Recent progress in multivariate splines, in: Approximation Theory IV (C. K. Chui, L. L. Schumaker, and J. D. Ward, eds.), Academic Press, New York, 1983, pp. 27-121.

[3] S. S. DRAGOMIR, Refinements of the Hermite-Hadamard integral inequality for log-convex functions, Austral. Math. Gazette 28 (2001), 129-134.

[4] S. S. DRAGOMIR AND B. Mond, Integral inequalities of Hadamard's type for log-convex functions, Demonstratio Math. 31(2) (1998), 354-364.

[5] S. S. Dragomir And C. E. M. Pearce, Selected Topics on Hermite-Hadamard Inequalities and Applications, RGMIA Monographs, Victoria University, 2000. (Online: http://rgmia.vu.edu.au/monographs/hermite_hadamard.html).

[6] E. Neuman, Inequalities involving multivariate convex functions II, Proc. Amer. Math. Soc., 109 (1990), 965-974.

[7] E. Neuman, The weighted logarithmic mean, J. Math. Anal. Appl., 188 (1994), 885-900.

[8] E. NeUman, Inequalities involving multivariate convex functions III, Rocky Mountain Math. J., 42 (2012), 251-256.

[9] E. NEUMAN AND J. PEČARIĆ, Inequalities involving multivariate convex functions, J. Math. Anal. Appl., 137(1989), 541-549.

[10] E. Neuman And J. SÁndor, Inequalities involving Stolarsky and Gini means, Math. Pannon., 14 (2003), 29-44.

[11] J. E. PeČarić, F. Proshan, And Y. L. Tong, Convex Functions, Partial Orderings and Statistical Applications, Academic Press, Boston, 1992. 